\title{
Genetic profiling of the Plasmodium falciparum parasite population in uncomplicated malaria from India
}

\author{
Amit Kumar, Shri Pat Singh, Rajendra Bhatt and Vineeta Singh*
}

\begin{abstract}
Background: The genetic complexity and the existence of several polymorphisms in parasites are the major hindrances for the malaria control programmes of the country. The genetic profiling in the parasite populations in India will provide useful baseline data for future studies elucidating the parasite structure and distribution of drug resistance genotypes in different regions.

Methods: The blood samples of symptomatic patients were collected and analysed for drug resistance genes (Pfcrt, Pfmdr-1, dhfr, dhps and k13) and gametocyte genes (Pfs25, Pfg377); in vitro drug sensitivity assay by schizont maturation inhibition (SMI) was also performed in adapted field isolates.

Results: Of the 122 field isolates analysed; 65.5\% showed Pfcrt K76T mutant alleles, 61.4\% Pfmdr-1 N86Y mutants, $59.5 \%$ dhfr mutants, $59.8 \%$ dhps mutants was observed, but no polymorphism was seen for $k 13$. The sequence analysis of Pfg 377 gene revealed five types of populations in the field isolates. The inhibitory concentrations $\left(\mathrm{IC}_{50}\right)$ for anti-malarial drugs viz chloroquine (CQ), artesunate (AS), were in the range of 10.11-113.2 nM and 2.26-4.08 nM, respectively, in the field isolates evaluate by in vitro assay. The $\mathrm{IC}_{50}$ values for $\mathrm{CQ}$ have shown a remarkable reduction on comparison with the previous available data, whereas a slight increase in the $\mathrm{IC}_{50}$ values for AS was observed in the study.

Conclusions: The increase in mutation rate in drug resistance allelic loci with inhibitory concentration of CQ and AS drugs was observed in the field isolates and high diversity in Pfg377 gametocyte gene indicate towards parasite multifactorial behaviour. The knowledge of the prevalent drug resistance genes is important for intervention measures to be successful and efforts should also be made to prevent transmission of P. falciparum.
\end{abstract}

Keywords: Plasmodium falciparum, Drug resistance genotyping, Pfg377gene

\section{Background}

Morbidity and mortality due to Plasmodium falciparum malaria have increased across Indian sub-geographical regions, largely because of the widespread resistance to chloroquine (CQ) and sulfadoxine-pyrimethamine (SP) leading to generation of regional heterogeneity in the target genes $[1,2]$. The rise in the incidences of malaria is largely attributed to the increase in the drug resistance parasites [3]. The emergence of chloroquine resistance

*Correspondence: vineetas_2000@yahoo.com

ICMR-National Institute of Malaria Research, Sector-8, Dwarka, New Delhi, India in India led to the change in the drug policy in the year 2005 to artemisinin-based combination therapy (ACT) as first-line of treatment [4]. The Pfcrt and Pfmdr-1 genes are associated with CQ resistance, whereas the $d h f r$ and $d h p s$ genes are related with SP resistance in the malaria parasite caused by the mutations present in these drug resistance genes [5]. The Kelch propeller domain (k13-propeller) in P. falciparum have been found to be associated with delayed parasite clearance after ACT therapy [6].

Plasmodium falciparum is transmitted from the human host to the mosquito vector during the sexual stage via gametocyte. But the transmissibility of $P$. falciparum is 
due to the relationship between the prevalence, duration and density of gametocyte carriage with variable and modulated by the immune response in the human host [7]. Gametocytes from multi-clone P. falciparum infections can persist three times longer than singleclone infections indicating that multiplicity of infection (MOI) promotes either longer persistence or continuous production of gametocytes [8]. The occurrence of sub-microscopic gametocytes in the parasite population play a major role in malaria transmission. It has also been shown that the microscopic diagnosis is more likely to underestimate the prevalence of gametocytes and more so in the sub-patent population of gametocytes [9]. For the successful elimination of $P$. falciparum it is crucial to limit the transmission of malaria parasites which can be achieved by reducing the carriage of viable gametocytes, hence it is important to investigate the drug resistance genes with gametocyte genes [9].
The aims of the present study were to determine the prevalence of $P f c r t, P f m d r-1, d h f r$ and $d h p s$ mutations in drug resistance genes with $k 13$ (particularly ACT with SP as partner drug and CQ) and $P f g 377$ genes with in vitro susceptibility assays in order to understand the genetic complexity of falciparum malaria in natural infections. The Pfcrt, Pfmdr-1, dhfr and dhps are directly implicated in parasite population turning resistant to anti-malarials and $P f g 377$ gene is considered under neutral/balancing selection. Coupling the analysis of drug resistance genes along with $k 13$ with in vitro studies will give an insight about the circulating parasite population in the region and profiling the chloroquine markers will provide data to know if there is any change at the genetic level for these markers after a change in the treatment policy.

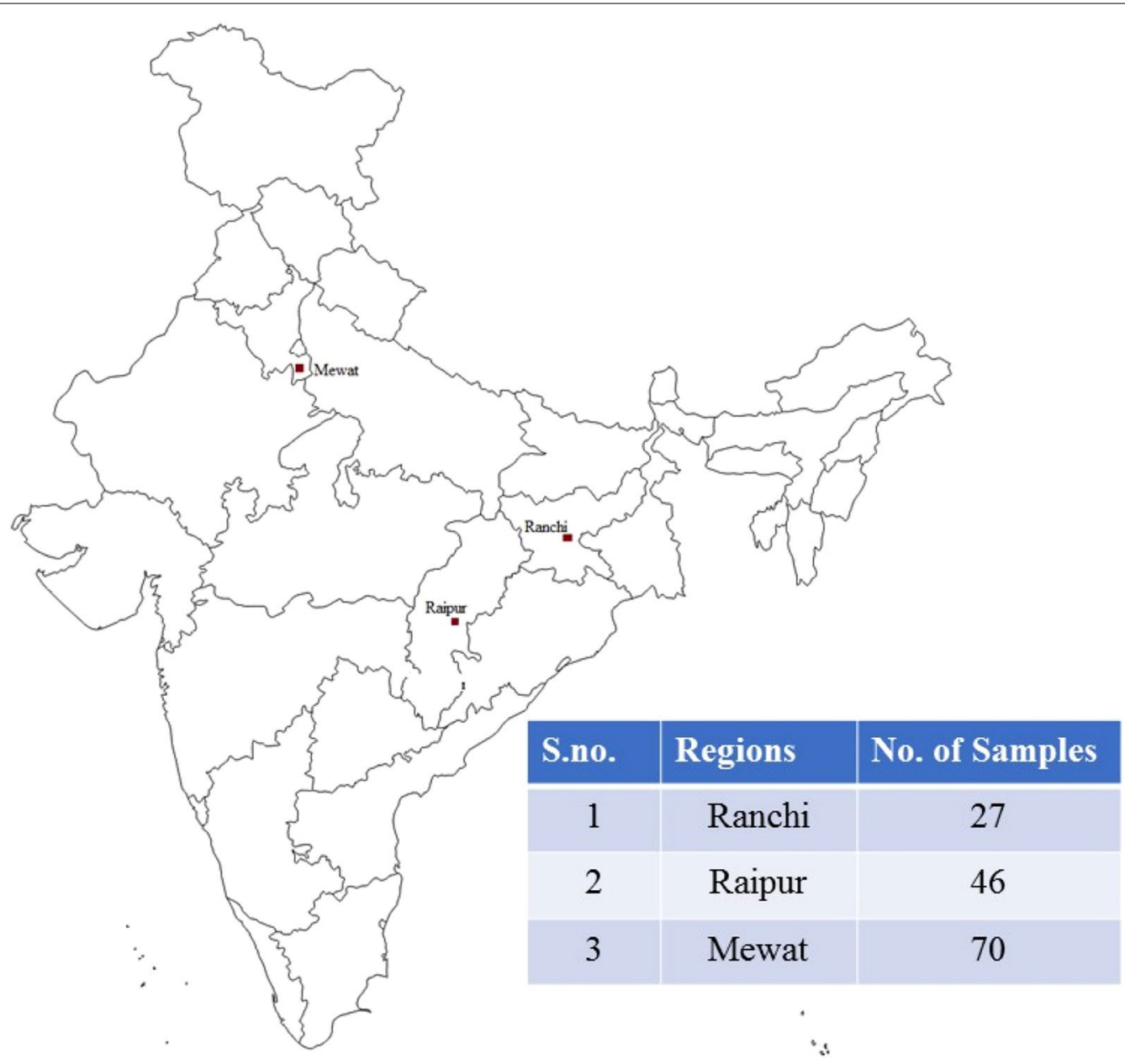

Fig. 1 Geographic map of India showing the study sites viz Mewat, Raipur and Ranchi with number of P. falciparum samples collected from the these sites 


\section{Methods}

\section{Study population and ethics}

In the present study, 143 malaria blood samples were collected from the primary health centres (PHCs) in Mewat, Raipur and Rourkela during the transmission season in the years 2015-2016 (Fig. 1). The study group comprised of patients of either sex, 5-60 years of age, with symptoms of malaria, but no history of prior medication until previous 30 days. Two microliter of venous blood from patients found to be $P$. falciparum positive by microscopy/RDT were collected in EDTA vacutainer tubes. $100 \mu$ l of the collected sample was used for filter paper spots, labelled and transported in the laboratory in sealed plastic envelopes and remaining samples were cryopreserved.

The institutional ethics committee (NIMR-IEC) approved the study (reference no. ECR/NIMR/EC/2) and the ethical guidelines of the Institute were followed for sample collection. Verbal and written informed consent was obtained from all patients/guardians in case of minors.

\section{Nucleic acid extraction}

The parasite genomic DNA from filter paper was extracted using QIAamp TM DNA mini kit (QIAGEN), according to the manufacturer's instructions (dried blood spots protocol) with slight modifications. DNA samples were kept at $-20^{\circ} \mathrm{C}$ until further processing.

\section{PCR analysis}

PCR assay for Plasmodium species: After the DNA extraction nested PCR assay with $18 \mathrm{~S}$ rRNA primers was performed to differentiate between the mixed infections of Plasmodium vivax and P. falciparum, as described previously [10].

\section{Genotyping of drug resistance genes}

The Pfcrt gene codon-76; Pfmdr-1 codon-86, dhfr codons-16, 51, 59, 108, 164; dhps gene codons-436, 437, 540, 581, 613 and $k 13$ gene were analysed as described earlier $[6,11,12]$. All PCR amplifications were performed with $1 \mu$ l of template DNA from samples including the negative controls and reference strain 3D7 as standard positive controls.

\section{PCR-RFLP assay}

After successful PCR amplification the polymorphisms in Pfcrt and Pfmdr-1 genes were determined by RFLP assay by digestion with ApoI and AflIII enzymes. The enzyme ApoI cleaves the Pfcrt-76K (the CQ sensitive isolates) but not Pfcrt-76T (as seen in CQ resistant isolates) and allele of $P f m d r-1-86 \mathrm{~N}$ (the CQ sensitive isolates) but not
Pfmdr-1-86Y (the CQ resistant isolates). AflIII was unable to digest the amplicon of the sensitive isolates.

\section{Sequence analysis}

The $k 13$ amplification reactions were carried out as described earlier and mutations were assessed by comparing each sequence with the reference 3D7 K13-propeller (PF3D7_1343700) [6]. The positive PCR products of dhfr and dhps genes were purified and sequenced on an ABI 3730 DNA analyzer. The 3D7 strain (GenBank ID: for dhfr 9221804 and dhps 2655294) was used as reference for comparing the gene sequences. The sequence comparisons was done with the Plasmo database of these two genes with basic local alignment search too $\mathrm{N}$ (BALST N) and MEGA software [13].

\section{Culture studies \\ Parasite culture}

In the laboratory, the cryopreserved samples were revived in the RPMI 1640 culture medium supplemented with gentamicin $(0.01 \mathrm{mg} / \mathrm{ml}), 25 \mathrm{mM}$ Hepes buffer, $25 \mathrm{mM} \mathrm{NaHCO}_{3}$ and $5 \%$ human serum maintained in 5\% $\mathrm{CO}_{2}$ with incubation at $37{ }^{\circ} \mathrm{C}$. The growth of the parasite in vitro was visualized daily by microscopic examination of the Giemsa-stained blood films [14].

\section{Gametocyte production}

The field isolates of $P$. falciparum were put to gametocyte production at $0.5 \%$ parasitaemia and $6 \%$ haematocrit under $3 \% \mathrm{O}_{2}, 5 \% \mathrm{CO}_{2}, 92 \% \mathrm{~N}_{2}$ gas. RPMI culture medium with $25 \mathrm{mM}$ HEPES, $50 \mathrm{mg} / \mathrm{l}$ hypoxanthine, $2 \mathrm{~g} /$ litre sodium bicarbonate, $10 \%$ human serum, no fresh erythrocytes were added to culture till 14 days. Under these conditions, gametocytes were visible from 7 th day.

\section{In vitro analysis}

The drug plates were prepared in $\mathrm{pmol} / \mathrm{l}$ as per the WHO in vitro microtest procedure by SMI assay [15]. CQ, AS (Sigma-Aldrich) stock solutions of $10 \mathrm{mM}$ concentrations were diluted two folds to coat the drug plates [16]. A $50 \mu \mathrm{l}$ of the blood media mixture (BMM) was added in the pre-dosed drug plate in triplicate with serial drug dilutions and then incubated in $\mathrm{CO}_{2}$ gas mixture at $37{ }^{\circ} \mathrm{C}$ for $24-30 \mathrm{~h}$ for schizont maturation. After $24 \mathrm{~h}$ incubation, a thin smear was prepared from the control well to observe mature schizonts and if more than $10 \%$ schizonts (with more than 3 nuclei) were seen in the control wells, it was considered to be valid. The thick smears were Giemsa-stained and the schizonts were counted out of a total of 200 asexual parasites for calculating $\mathrm{IC}_{50}$ values. For the test, the 3D7 was used as the reference strain with 
a mean $19.1 \mathrm{nM}$ and $2.4 \mathrm{nM} \mathrm{IC}$ 50 value for $\mathrm{CQ}$ and $\mathrm{AS}$, respectively.

\section{Detection of gametocyte genes}

Pfs 25 and Pfg377gene: The PCR analysis for Pfs 25 and Pfg377 genes in the patient samples were carried out using the PCR conditions with high fidelity Taq DNA polymerase as described previously (ThermoFisher Taq) $[16,17]$.

\section{Sequence analysis}

The nested PCR products for region 3 of Pfg377 were purified and sequenced using the cycle sequencing reaction with ABI Big Dye terminator version 3.1. The Pfg377 gene of 3D7 strain (genID: Pf 3D7_1250100) was used as reference for sequence comparisons of the field isolates. The sequences were then assembled, aligned and edited using MEGA 6 and Finch TV program [13].

\section{Statistical analyses}

The aligned $d h f r$, dhps and Pfg377 gene sequences were used to determine the number of haplotypes. Also $\theta$ and $\pi$, the two measures of nucleotide diversities were estimated for each parasite population in each region [18]. The $\pi$ nucleotide diversity parameter is based on the average number of pairwise nucleotide differences per site and $\theta$ estimates is dependent on the number of segregating sites. All these were estimated using DnaSP version 5.10.01 [18].

\section{Results}

\section{Samples}

Out of the total 143 samples analysed for mixed infections of Plasmodium spp. six samples were found to be of mixed infections with $P$. falciparum and $P$. vivax. Only $P$. falciparum mono-infections 122 sample (single parasite infections) were analysed in this study and $P$. vivax and co-infections were not further proceeded for any other examination. No follow up study was done to evaluate the parasite clearance in the patients hence the clinical data on delayed asexual stage parasite clearance was not available.

\section{Drug resistance genes}

Table 1 gives the distribution of these genes in the three studied population.

\section{Pfcrt, Pfmdr-1 gene alleles and $k 13$}

Pfcrt gene was examined for K76T allele and was successfully amplified in 122 of field isolates. After digestion with ApoI enzyme the mutant allele $76 \mathrm{~T}$ was seen in 80 (65\%) in samples and $42(37.4 \%)$ were wild type isolates indicating their sensitivity to CQ (Table 1).

The $P f m d r-1$ gene amplicons were digested by restriction enzyme AflIII. Upon digestion, different patterns of $\mathrm{N} 86 \mathrm{Y}$ were observed where wild $\mathrm{N}$-codon was in 47 isolates $(38.5 \%)$ wild and mutant Y-codon in 75 isolates (61.4\%) and mixed N/Y in two isolates (2.46\%). We did not observe any significant correlation between the Pfcrt K76T and $P f m d r-1$ N86Y SNPs in the study (Table 1). The $k 13$ amplified did not reveal any synonymous or non-synonymous prevalent mutations in the field isolates.

\section{dhfr and dhps genes}

The dhfr and dhps genes for SP were sequence analysed for the presence of mutations in 122 and 121 isolates respectively. Different isolates showed presence of different SNPs and a rise in double and triple mutations was observed in both the genes (Table 2). In $d h f r$ gene the mutant 59R associated with high-level SP resistance was found to be $42.6 \%$ and for codons $51 \mathrm{I}, 108 \mathrm{~N}$ and $164 \mathrm{~L}$ mutants were observed at $31.9 \%, 17.2 \%$ and $7.3 \%$ in the population respectively. The wild genotype for $d h f r$ was seen at higher frequency in Raipur with $37.5 \%$ followed by $27.2 \%$ in Ranchi and $22.9 \%$ in Mewat regions.

The dhps gene mutations at codon $436 \mathrm{~F}$ was $47.4 \%$ and $540 \mathrm{E}$ was $42.6 \%$ respectively whereas $437 \mathrm{G}, 581 \mathrm{G}$ and $613 \mathrm{~T}$ occured at $7.3 \%, 5.7 \%$ and $1.6 \%$, respectively. In dhps gene the wild type field isolates were highest in Mewat region with $23.7 \%$ followed by $13.1 \%$ in Raipur

Table 1 Percentage of drug resistance mutations seen in the parasite population at the three sites of the country viz Ranchi, Raipur and Mewat

\begin{tabular}{|c|c|c|c|c|}
\hline \multirow[t]{2}{*}{ Region } & \multicolumn{4}{|c|}{ Drug resistance genes } \\
\hline & Pfcrt (K76T) & Pfmdr-1 (N86Y) & $\operatorname{Dhfr}(16,51,59,108,164)$ & $\begin{array}{l}\text { Dhps (436, } \\
437,540,581, \\
613)\end{array}$ \\
\hline Ranchi, Mutant & $18(81.81)$ & $20(90.9)$ & $16(72.7)$ & $18(81.81)$ \\
\hline Raipur, Mutant & $31(77.5)$ & $22(55)$ & $25(62.5)$ & $24(60)$ \\
\hline Mewat, Mutant & $31(51.7)$ & $33(55)$ & $32(53.3)$ & $31(51.7)$ \\
\hline
\end{tabular}

Values in the parenthesis indicate the percentage of isolates in the specific category 
Table 2 Nucleotide diversity in dhfr and dhps allelic loci in sub-population areas with their different test parameters

\begin{tabular}{|c|c|c|c|c|c|c|}
\hline \multirow[t]{3}{*}{ No. of samples (n) } & \multicolumn{3}{|l|}{ dhfr } & \multicolumn{3}{|l|}{ dhps } \\
\hline & Ranchi & Raipur & Mewat & Ranchi & Raipur & Mewat \\
\hline & 22 & 40 & 60 & 22 & 40 & 60 \\
\hline Mutant (\%) & $16(72.70)$ & $25(62.50)$ & $32(53.30)$ & $18(81.80)$ & $24(60)$ & $31(51.60)$ \\
\hline $\begin{array}{l}\text { SNP }(n) \text { total number of mutant alleles } \\
\text { found in different regions }\end{array}$ & 27 & 46 & 52 & 38 & 41 & 50 \\
\hline Nucleotide diversity: $\Theta$ & 1.09 & 0.9 & 0.8 & 1.09 & 0.4 & 1.07 \\
\hline Pairwise difference: $\pi$ & 1.13 & 1.11 & 1.35 & 0.8 & 1.02 & 1.31 \\
\hline \multicolumn{7}{|l|}{ Test of neutrality } \\
\hline Tajima's D & 0.094473 & 0.437752 & 1.276397 & -0.747549 & 2.225384 & 0.526865 \\
\hline Fu and Li's D* & 0.142505 & -0.07277 & 0.986851 & -0.81047 & 0.771237 & 1.080688 \\
\hline Fu and $L i F^{*}$ & 0.137096 & -0.698455 & 1.197038 & -0.842395 & 1.297203 & 1.00836 \\
\hline
\end{tabular}

Tajima's D, Fu, Li's D* and Li F* test used for standardized measure of average number of mutations between pairs in the sample. Nucleotide diversity ( $\Theta$ ) and pairwise difference $(\pi)$ indicates the distribution of mutation rate which varies among the regions. \# Total number of field isolates in the parenthesis for that particular region. $P$ value for all the three sites for the two genes was found to be non-significant $(<0.05)$

and 3.2\% least in Ranchi (Table 2). The triple mutation associated with high level SP resistance 51I R59 N108 was highest in Mewat followed by Raipur and Ranchi with $36 \%, 35.4 \%$ and $20.4 \%$, respectively.

\section{Genetic diversity analysis}

The sequence analysis of $d h f r$ and $d h p s$ genes revealed highest nucleotide diversity in Ranchi for both the genes where the $\theta$ and $\pi$ estimates of $P$. falciparum isolates showed an increase in the nucleotide diversity on comparison with Raipur and Mewat (Table 2). The $\pi$ values suggest slight increase in intermediate frequency mutations in the population. The neutrality tests show no statistically significant results for the tests carried out for any divergence in both genes in the study population (Table 2).

\section{Sequence analysis}

The region 3 of $P f g 377$ gene was included in the study as it is the most polymorphic region and hence used in allele typing. Sequencing the 3 regions of the $P f g 377$ gene was carried out for 122 isolates revealed the deletion of $21 \mathrm{bp}$ and multiples of $21 \mathrm{bp}$. On comparison with NF54 reference sequence, the isolates showed seven different types of deletions viz NHHIDHQ, HNHHIDH, HNHHIDHHNHHIDH, DHHIDHH, NHHIDHH, NHHIDHHNHHIDHQ and NHHIDHHNHHIDHHDHHIDHHDHHIDHH amino acid fragments. The most commonly occurring deletion was HNHHIDH, found in 42 isolates. The isolates with no deletions exhibited DHHI, DHH and NHHI sequence repeats 4, 9 and 7 times, respectively. These repeats occurred at different frequencies in the other forty isolates repeating these sequences 4, 8 and 6 times, respectively. On the basis of these deletions five types of genotype was present in the field isolates and He for $P f g 377$ gene was found to be 0.75 . Two new mutations-D924N and H888Q mutation was found in four and nine isolates respectively on sequence analysis (Fig. 2).

Combining the mutational analysis of the dhfr, dhps and $P f g 377$ genes 18 haplotypes were observed in the present study in all the populations (Table 3). Among these haplotypes most prevalent was A10 commonly seen in Raipur and haplotype A18 depicted the wild population $(\mathrm{n}=44)$ seen distributed randomly in Mewat $(45 \%)$, Raipur (37.5\%) and Ranchi (9\%). The combined results of $d h f r$ and dhps mutational analysis reveals highest polymorphisms in parasite populations from 77.7 and $81.8 \%$ respectively in Ranchi.

\section{Phylogenetic analysis of $d h f r, d h p s$ and $P f g 377$ genes}

To identify the existing genetic diversity in the parasite population the radial cladogram network was constructed between the drug resistance loci $d h f r$, dhps and gametocyte gene $P f g 377$ by using Dendroscope version 3.5.9 software [19]. The genetic relatedness is determined by clade in each phylogeny tree which signify the similarity in the various isolates. In $d h f r$ phylogeny tree we find that the isolates were divided in two clades: the first clade was formed by the wild type isolates along with the reference strain and the second clade comprises of isolates having mutant alleles. The mutant clade consists of different sub-group clades within isolates having single, double or triple mutations (Fig. 3a). The sub-group clade subdivisions in different colours depicts the different mutations in the populations. The most predominant mutation clade in the cladogram consists of 59 and 108 codons while the least prevalent 108 mutations made 


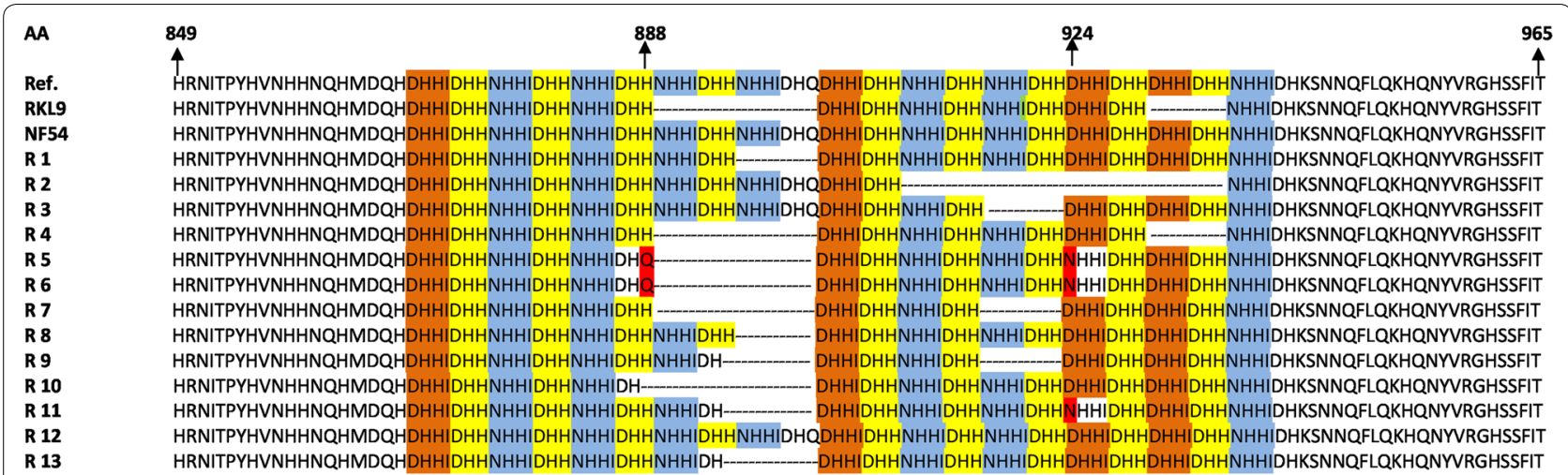

Fig. 2 Sequence analysis of Pfg377 alleles in the field isolates of P. falciparum with three reference strain 3D7, NF54 and resistant strain RKL9. The colour-coded base pair represent the repeated aminoacid (AA) sequence viz DHHI formed four times, DHH nine times and NHHI repeated seven times; varying within isolates. The dotted symbol shows various deletions-21 bp, 42 bp, 63 bp, 83 bp. Two new mutations in the sequence at codon position 888 histidine $(\mathrm{H})$ to glutamine $(\mathrm{Q})$ (in turquoise blue colour) and at 924 position aspartic acid (D) to asparagine (N) (in green colour) are also reported

Table 3 The distribution of haplotypes (A1-A18) based upon the mutation codon differentiation for Pfcrt, Pfmdr-1, Pfdhfr, Pfdhps and Pfg377 genes

\begin{tabular}{|c|c|c|c|c|c|c|c|}
\hline Haplotype & Pfcrt & Pfmdr-1 & $d h f r$ & dhps & Pfg377 (bp deletions) & No. of isolates & $\%$ frequency \\
\hline A1 & $76 \mathrm{~T}$ & $86 Y$ & $51 \mathrm{I}, 59 \mathrm{R}, 108 \mathrm{~N}, 164 \mathrm{~L}$ & 436F, 437A, 540E, 581A, 613T & 21,63 & 1 & 0.8 \\
\hline A2 & $76 \mathrm{~T}$ & $86 Y$ & $51 \mathrm{l}, 59 \mathrm{R}, 108 \mathrm{~N}, 164 \mathrm{I}$ & $436 \mathrm{~F}, 437 \mathrm{G}, 540 \mathrm{E}, 581 \mathrm{~A}, 613 \mathrm{~A}$ & 21,63 & 1 & 0.8 \\
\hline A3 & $76 \mathrm{~T}$ & $86 Y$ & $511,59 R, 108 \mathrm{~N}, 164 \mathrm{I}$ & $436 \mathrm{~F}, 437 \mathrm{~A}, 540 \mathrm{E}, 581 \mathrm{~A}, 613 \mathrm{~A}$ & 21,63 & 1 & 0.8 \\
\hline A4 & $76 \mathrm{~T}$ & $86 Y$ & $51 \mathrm{l}, 59 \mathrm{R}, 108 \mathrm{~N}, 164 \mathrm{I}$ & $436 \mathrm{~F}, 437 \mathrm{~A}, 540 \mathrm{E}, 581 \mathrm{~A}, 613 \mathrm{~A}$ & 21 & 7 & 5.7 \\
\hline A5 & $76 \mathrm{~T}$ & $86 Y$ & $51 \mathrm{~N}, 59 \mathrm{R}, 108 \mathrm{~S}, 164 \mathrm{I}$ & $436 \mathrm{~F}, 437 \mathrm{~A}, 540 \mathrm{E}, 581 \mathrm{~A}, 613 \mathrm{~A}$ & 63 & 9 & 7.3 \\
\hline A6 & $76 \mathrm{~T}$ & $86 Y$ & $51 \mathrm{~N}, 59 \mathrm{C}, 108 \mathrm{~S}, 164 \mathrm{I}$ & $436 \mathrm{~F}, 537 \mathrm{~A}, 540 \mathrm{E}, 581 \mathrm{~A}, 613 \mathrm{~A}$ & 21,63 & 1 & 0.8 \\
\hline A7 & $76 \mathrm{~T}$ & $86 Y$ & $51 \mathrm{I}, 59 \mathrm{C}, 108 \mathrm{~S}, 164 \mathrm{I}$ & $436 \mathrm{~F}, 437 \mathrm{~A}, 540 \mathrm{~K}, 581 \mathrm{~A}, 613 \mathrm{~A}$ & 83 & 1 & 0.8 \\
\hline A8 & $76 \mathrm{~T}$ & $86 Y$ & $51 \mathrm{~N}, 59 \mathrm{C}, 108 \mathrm{~S}, 164 \mathrm{~L}$ & $436 \mathrm{~S}, 437 \mathrm{~A}, 540 \mathrm{~K}, 581 \mathrm{~A}, 613 \mathrm{~A}$ & $63,42,83$ & 1 & 0.8 \\
\hline A9 & $76 \mathrm{~T}$ & $86 Y$ & $51 \mathrm{~N}, 59 \mathrm{C}, 108 \mathrm{~N}, 164 \mathrm{I}$ & $436 \mathrm{~S}, 437 \mathrm{~A}, 540 \mathrm{~K}, 581 \mathrm{~A}, 613 \mathrm{~A}$ & $21,63,42$ & 2 & 1.6 \\
\hline A10 & $76 \mathrm{~T}$ & $86 Y$ & $51 \mathrm{~N}, 59 \mathrm{R}, 108 \mathrm{~N}, 164 \mathrm{I}$ & $436 \mathrm{~F}, 437 \mathrm{~A}, 540 \mathrm{~K}, 581 \mathrm{E}, 613 \mathrm{~A}$ & 21 & 21 & 17.2 \\
\hline A11 & $76 \mathrm{~T}$ & $86 Y$ & $511,59 \mathrm{R}, 108 \mathrm{~N}, 164 \mathrm{~L}$ & $436 \mathrm{~F}, 437 \mathrm{G}, 540 \mathrm{E}, 581 \mathrm{~A}, 613 \mathrm{~A}$ & 21 & 8 & 6.5 \\
\hline A12 & $76 \mathrm{~T}$ & $86 Y$ & $51 \mathrm{I}, 59 \mathrm{R}, 108 \mathrm{~N}, 164 \mathrm{I}$ & $436 \mathrm{~F}, 437 \mathrm{~A}, 540 \mathrm{E}, 581 \mathrm{G}, 613 \mathrm{~A}$ & 21 & 5 & 4 \\
\hline A13 & $76 \mathrm{~T}$ & $86 Y$ & $51 \mathrm{l}, 59 \mathrm{R}, 108 \mathrm{~N}, 164 \mathrm{I}$ & 436F, 437A, 540K, 581G, 613T & 21 & 2 & 1.6 \\
\hline A14 & $76 \mathrm{~T}$ & $86 Y$ & $51 \mathrm{I}, 59 \mathrm{C}, 108 \mathrm{~N}, 164 \mathrm{I}$ & $436 \mathrm{~F}, 437 \mathrm{~A}, 540 \mathrm{~K}, 581 \mathrm{~A}, 613 \mathrm{~A}$ & - & 1 & 0.8 \\
\hline A15 & $76 \mathrm{~T}$ & $86 Y$ & $51 \mathrm{~N}, 59 \mathrm{C}, 108 \mathrm{~S}, 164 \mathrm{I}$ & 436F, 437A, 540K, 581A, 613A & 21 & 3 & 2.4 \\
\hline A16 & $76 \mathrm{~T}$ & $86 Y$ & $51 \mathrm{~N}, 59 \mathrm{C}, 108 \mathrm{~S}, 164 \mathrm{I}$ & $436 \mathrm{~S}, 437 \mathrm{~A}, 540 \mathrm{~K}, 581 \mathrm{~A}, 613 \mathrm{~A}$ & - & 12 & 9.8 \\
\hline A17 & $76 K$ & $86 Y$ & $51 \mathrm{~N}, 59 \mathrm{C}, 108 \mathrm{~S}, 164 \mathrm{I}$ & $436 \mathrm{~S}, 437 \mathrm{~A}, 540 \mathrm{~K}, 581 \mathrm{~A}, 613 \mathrm{~A}$ & - & 2 & 1.6 \\
\hline A18 & $76 \mathrm{~K}$ & $86 N$ & $51 \mathrm{~N}, 59 \mathrm{C}, 108 \mathrm{~S}, 164 \mathrm{I}$ & $436 \mathrm{~S}, 437 \mathrm{~A}, 540 \mathrm{~K}, 581 \mathrm{~A}, 613 \mathrm{~A}$ & - & 44 & 36 \\
\hline
\end{tabular}

A18 is the wild type haplotype (drug resistance genes) found in the studied isolates

the other clade. The same sequence relatedness was also found in dhps allelic profiling (Fig. 3b). The most predominant in this allelic profile was 436 followed by 540 codons and the least one was codon 613 position. In Pfg377 the clades are similar with variations due to short sequence deletions and repeats among the population (Fig. 3c). The gene distribution shows no particular pattern for any mutant alleles of dhps and dhfr distributed across the country and to any particular region (Fig. 3a, b). Similarly, for $P f g 377$ gene too no distinct pattern for deletions or repeats were seen, with all randomly distributed in the population (Fig. 3c).

\section{Culture studies}

The cryopreserved samples were subjected to in vitro culture for revival and 44 isolates adapted in culture. After successful establishment of culture adapted 


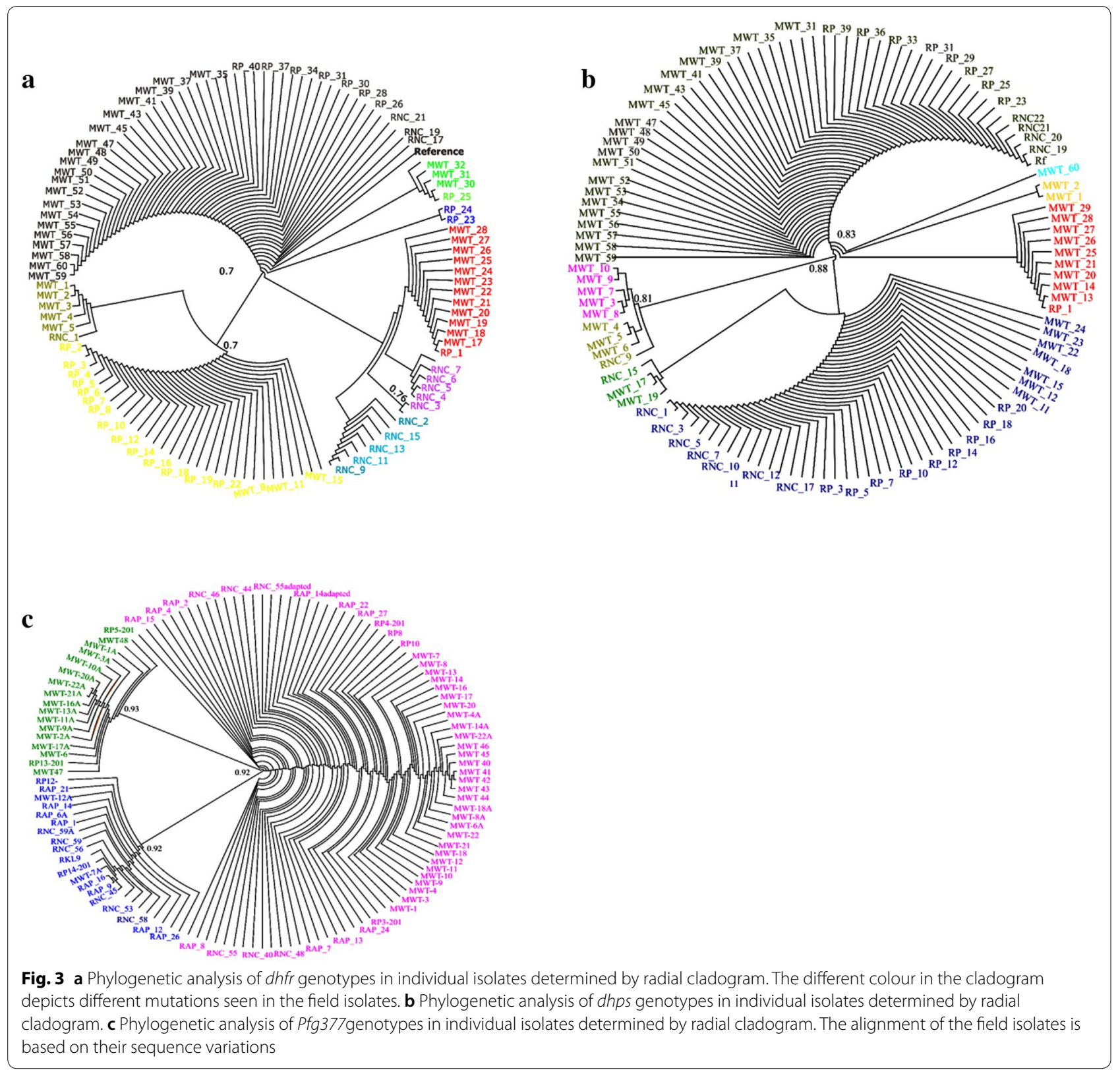

samples, the isolates were put for gametocyte production in vitro. After 15 days of culturing in laboratory, 10 field isolates produced gametocytes and various stages I-V were identified by microscopy. From 7th day onwards post sub-culture, different stages of gametocytes were seen in smears. In two isolates no gametocyte production was seen though the asexual stages were identified in smears during culture adaptation in laboratory.

\section{In vitro drug sensitivity assay}

Due to limited volume of cryopreserved samples it was technically difficult to analyse with all anti-malarial drugs hence only primary drugs-CQ and AS in vitro sensitivity assay was performed using the SMI assay. The CQ resistant isolates showed schizont maturation at $8 \mathrm{pmol}$ or more and for AS no resistance was seen in isolates. The inhibitory concentrations $\left(\mathrm{IC}_{50}\right)$ for the $\mathrm{CQ}$ and AS, drugs were found in the range of 10.11-113.2 nM, $2.26-4.08 \mathrm{nM}$, respectively in the evaluated field isolates (Fig. 4a). The $\mathrm{IC}_{50}$ values for CQ have shown a remarkable reduction on comparison with the previous available 


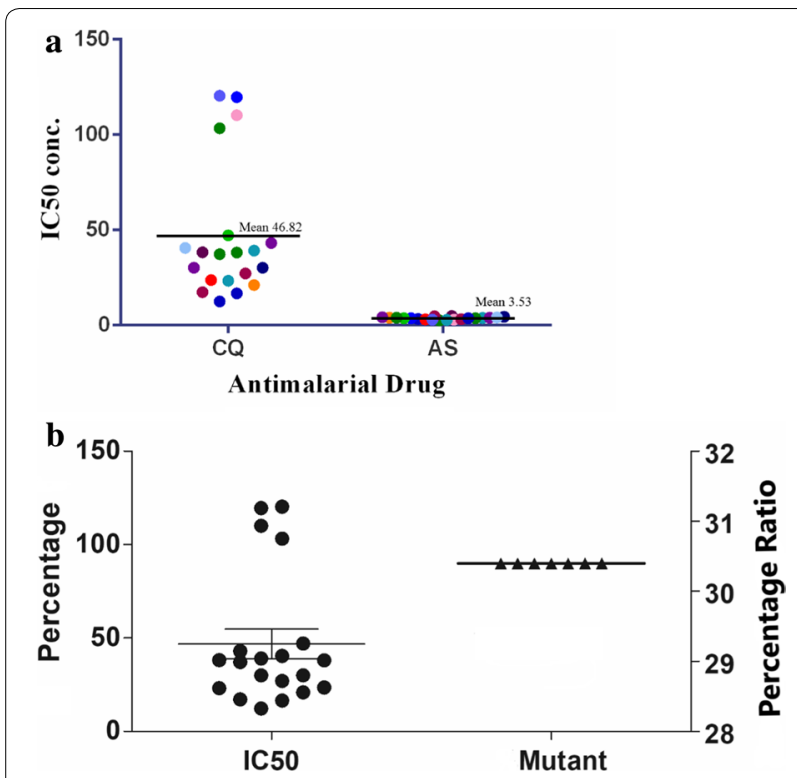

Fig. 4 a The $I C_{50}$ pattern of the field isolates (represented by coloured dots) tested for chloroquine (CQ) and artesunate (AS) drug. $\mathbf{b}$ Graph showing the comparative analysis of inhibitory concentration $\left(\mathrm{IC}_{50}\right)$ of adapted isolates with K76T (PfCrt) mutant isolates after sequencing analysis (X-axis). The percentage values of field isolates for both analysis shows the accordance of results in them

data, whereas a slight increase in the $\mathrm{IC}_{50}$ values for AS were observed. On comparing the $\mathrm{IC}_{50}$ values with the sequencing data of the field isolates it was observed that the isolates which had high $\mathrm{IC}_{50}$ values also harboured the K76T mutations in the Pfcrt gene (Fig. 4b). Two isolates which were resistant to CQ (MWT 16 and 17) also had high $\mathrm{IC}_{50}$ for AS values indicating an increase in the tolerance value for AS drug. MWT-14 and MWT-20 were found to have high $\mathrm{IC}_{50}$ values for both the tested drugs though MWT-14 was a single clone and MWT20 a multiclone on analysis. Due to the unavailability of required sample volume the Ring-stage Survival Assay (RSA) for the samples was not carried out and only CQ and $\mathrm{AS} \mathrm{IC} \mathrm{IC}_{50}$ values were analysed in limited samples.

\section{Discussion}

The malaria situation continues to prevail even after intensive control efforts and remains persistent in India; as India is a major hot-spot for malaria transmission due to its unique favourable topography with respect to malaria survival [20]. Drug resistance is a major hurdle in malaria control not only in the country but worldwide too [21]. Continuous monitoring of the drug resistance provides warning signals to drug policy makers. The emergence of drug-resistant parasites in India is still on the rise even after the introduction of $\mathrm{ACT}$ in the country [4]. Genotyping of Pfcrt, Pfmdr-1, dhfr, dhps genes and $k 13$ was carried out in field isolates of $P$. falciparum collected from Ranchi, Raipur and Mewat to determine the prevalence of polymorphisms in these genes along with the neutral gametocyte gene viz Pfg377. Not many such studies have been reported from India.

In the study, non-drug resistant Pfg377gene showed lot of genetic diversity in the field isolates which agrees with the observed random association between the loci and absence of regional differentiation among the $P$. falciparum isolates is in accordance with other reports [22, 23]. CQ resistance (CQR) was monitored on the point mutation detected in the Pfcrt and Pfmdr-1 genes by PCR-RFLP method where a high prevalence of mutant K76T Pfcrt and N86Y Pfmdr-1 alleles was observed. This holds true with the previous studies stating the role of $P f c r t$ gene crucial in detection of CQR in P. falciparum field isolates [24-26]. No linkage disequilibrium (LD) between the N86Y and K76T mutations in Pfmdr-1 and Pfcrt genes was observed and more number of samples are to be studied to compare the LD association in $P$. falciparum isolates. It is extremely important to routinely detect/analyse the pattern of drug resistance in malarial parasites which play not only an important role in the epidemiological surveys but also help in improvising/ updating the anti-malarial drug policies of the country. The CQ resistance if $P$. falciparum is mainly linked to the mutation in K76T codon of Pfcrt gene followed by Pfmdr-1 gene N86Y [24, 25].

SP are the partner drugs in the current ACT therapy of the country and we observed a high prevalence of more than one mutations in the dhfr, dhps genes of P. falciparum [27]. The double mutants 51I $108 \mathrm{~N}$ in the $d h f r$ gene were present at a higher frequency in the population as compared to the triple mutant 51I 59R $108 \mathrm{~N}$ associated with high resistance for SP was only seen in the field isolates from Mewat [28]. It has been reported from Africa and South East Asia earlier that I51 R59 N108 are highly SP resistant haplotype and the presence of this genotype in the studied population reveals that the parasite population is possibly moving towards SP resistance where evidence of selection is seen earlier in $d h f r$ gene than dhps gene $[29,30]$. This indicates the possibility of high resistant genotypes evolving in the parasite population due to constant drug pressure experienced by the parasite [31]. The $\pi$ values of nucleotide diversity were higher for dhfr and dhps genes in Mewat and similar in Ranchi and Raipur the endemic regions for malaria similarly documented from other places [32]. Analysing the SNPs in these drug resistance genes to find new mutations will help us to understand genetic changes leading to altered phenotypic traits better and also give an insight into the 
evolving genetic recombinations with respect to the current drug therapy [33]. The usage of ACT in the national drug policy since a decade is expected to decrease the $\mathrm{CQ}$ resistance and restore the CQ sensitive parasite population as such a change has been reported from several countries and $31.8 \%$ wild type of isolates in the parasite population was also seen in the present study [34].

Similarly, though the majority of isolates were found to be resistant to $C Q$, the $\mathrm{IC}_{50}$ observed value for $\mathrm{CQ}$ was comparatively low as seen in other reports [35]. This low value is indicative of the fact that the absence of CQ in malaria treatment has released the drug pressure with a possibility of moving towards being CQ sensitive in future as reported from other parts of the world [36]. The field isolates were found to be AS sensitive through with high $\mathrm{IC}_{50}$ values. Due to constant exposure to AS the increase in the drug pressure is likely to be responsible for increase in the $\mathrm{IC}_{50}$ values and another plausible explanation also could be the indiscriminate use of the drug resulting in slow rise of low level resistance in the parasite population [37]. In vitro drug sensitivity remains an important tool to assess the efficacy of the antimalarial drugs. The change of anti-malarial treatment in the country from CQ to ACT is expected to decrease the CQR population and might be leading to restore the sensitivity to $C Q$ as reported from other places [38]. The levels of parasitaemia varied in the infections and only 44 samples could be culture adapted. The difference in the growth pattern in different field isolates may be due to their difference in commitment to differentiate into asexual or sexual stages [39]. The expression profile of Pfg377 gene was correlated with the efficiency of gametocyte production in the above isolates. It was observed that isolates which produce mature gametocytes in vitro also showed an increase in thePfg377 gene expression from 1.00 to 4.56 -fold when compared to NF54 reference strain. The results suggested that a correlation between Pfg377 gene expression and the ability to produce gametocyte (mature) by the isolate exists as also reported by others [40].

The allele typing of $P f g 377$-the sexual stage specific gene in the field isolates revealed several allele types present in them. By conventional PCR only the predominant genotype was detected in the PCR results and presence of more than one clone in a single infection were observed on sequence analysis. This shows that this gene can be effectively used for detecting the presence of gametocyte producing multiclones in the field isolates. The presence of different genotypes/clones in the same infection is an important source of transmission [8]. The large number of repeats found in this gene is responsible for the high variability seen in parasites thus allowing several parasite lines to merge and survive simultaneously leading to transmission dynamics [41]. It is understood that presence of mixed gametocyte genotypes in the same sample is responsible for harbouring gametocytes for a significantly longer period of time on comparison with a single genotype where it was cleared three times faster than multiple clones [42]. Natural infections of $P$. falciparum seem to harbour multiple genotypes in the same host which could be due to the transmission burden in endemic regions but still, this knowledge does not improve the understanding of existing multiplicity in parasite biology [43].

By substantiating the results obtained from the genome sequence of $P$. falciparum and phylogenetic analysis, a basic idea about the population genetic structure was inferred. The phylogenetic trees of all three genes divided the isolates into two clear clades that can potentially be divided into further subgroups. However, no obvious cluster was observed and the distribution of isolates within the subgroups was random. There was no apparent trend for sequences of the same geographic region to be more closely related. The non-availability of wild-type of isolates limits our understanding of wild type parasites $v s$ drug-resistant parasites as most of the infections had at least single/double SNPs in drug resistance genes with extensive diversity present in the Pfg377 gene. More comprehensive studies like this are needed to understand the emerging complexity in the parasite population. The gametocyte data in relation to diversity level is too limited in Indian context. Our main focus to include this data was to generate data for any type of correlation between the mutation in drug resistance genes and gametocyte gene as these gametocyte genes play a crucial role in transmission as it gives baseline data for further work in this area.

\section{Conclusion}

This study provides information on drug resistance phenotypes, which have a critical role to play in malaria transmission. The increasing mutation rates in $d h f r, d h p s$ genes, existing diversity in the Pfcrt, Pfmdr-1 and Pfg377 genes, increase in the $\mathrm{IC}_{50}$ values for AS, in the parasite population indicates that as the parasite genetic diversity is multifactorial; the emergence of drug resistant genotypes need to be tackled by multipronged approach. The knowledge of the host dynamics with its epidemiological and evolutionary consequences is important for intervention measures to be successful and efforts should also be made to prevent transmission of $P$. falciparum. To assess the resistance dynamics and the surveillance of molecular markers of drug resistance is essential as it helps in selecting the most effective treatment and also should help in malaria intervention programmes. 


\begin{abstract}
Abbreviations
Pf: Plasmodium falciparum; crt: chloroquine resistance transporter; mdr: multidrug resistance; $d h f r$ dihydrofolate reductase; $d$ hps: dihydropteroate synthase; msp: merozoite surface protein; $I_{50}$ : inhibitory concentrations; SMI: schizont maturation inhibition; MOI: multiplicity of infection; BMM: blood media mixture; CQ: chloroquine; $\mathrm{AS}$ : artesunate; $\mathrm{ACT}$ : artemisinin-based combination therapy; RFLP: restriction fragment length polymorphism.
\end{abstract}

\section{Acknowledgements}

We acknowledge the support of all the members of Parasite Bank at National Institute of Malaria Research. Amit Kumar is an ICMR senior research fellow.

\section{Authors' contributions}

VS and AK conceived and designed the experiments. AK performed the experiments. SPS, RB helped in sample collection and with AK and VS analysed the data. AK and VS wrote the manuscript. VS made the critical revision and final draft of the manuscript. All authors read and approved the final manuscript.

\section{Funding}

This work was supported by funding from ICMR—(ICMR Grant No. 5/8-7(247)N-2012-ECD-II).

\section{Availability of data and materials}

The data used in this study is available from the corresponding author upon reasonable request.

\section{Ethics approval and consent to participate}

The study was approved by the institutional ethics committee (IEC) and written consent was taken from the patients before samples were collected (ECR/ NIMR/EC/2011/108).

\section{Consent for publication}

Not applicable.

\section{Competing interests}

The authors declare that they have no competing interests.

Received: 15 May 2019 Accepted: 21 November 2019

Published online: 02 December 2019

\section{References}

1. WHO. World malaria report 2017. Geneva: World Health Organization; 2017.

2. Gomes AR, Bushell E, Schwach F, Girling G, Anar B, Quail MA, et al. A genome-scale vector resource enables high-throughput reverse genetic screening in a malaria parasite. Cell Host Microbe. 2015;17:404-13.

3. Muhsin AM, Mackinnon MJ, Ali E, Nassir EK, Suleiman S, Ahmed S, et al. Evolution of drug-resistance genes in Plasmodium falciparum in an area of seasonal malaria transmission in Eastern Sudan. J Infect Dis. 2004;189:1239-44.

4. National Vector Borne Diseases. Guidelines for malaria diagnosis and treatment. 2014.

5. Haldar K, Bhattacharjee S, Safeukui I. Drug resistance in Plasmodium. Nat Rev Microbiol. 2018;16:156-70.

6. Ariey F, Witkowski B, Amaratunga C, Beghain J, Langlois AC, Khim N, et al. A molecular marker of artemisinin-resistant Plasmodium falciparum malaria. Nature. 2014;505:50-5.

7. Bousema T, Drakeley C. Epidemiology and infectivity of Plasmodium falciparum and Plasmodium vivax gametocytes in relation to malaria control and elimination. Clin Microbiol Rev. 2011;24:377-410.

8. Wampfler R, Timinao L, Beck HP, Soulama I, Tiono AB, Siba P, et al. Novel genotyping tools for investigating transmission dynamics of Plasmodium falciparum. J Infect Dis. 2014;210:1188-97.

9. Golassa L, Enweji N, Erko B, Aseffa A, Swedberg G. Detection of a substantial number of sub-microscopic Plasmodium falciparum infections by polymerase chain reaction: a potential threat to malaria control and diagnosis in Ethiopia. Malar J. 2013;12:352.

10. Johnston SP, Pieniazek NJ, Xayavong MV, Slemenda SB, Wilkins PP, da Silva AJ. PCR as a confirmatory technique for laboratory diagnosis of malaria. J Clin Microbiol. 2006;44:1087-9.

11. Dajem SM, Al-Farsi HM, Al-Hashami ZS, Al-Sheikh AA, Al-Qahtani A, Babiker HA. Distribution of drug resistance genotypes in Plasmodium falciparum in an area of limited parasite diversity in Saudi Arabia. Am J Trop Med Hyg. 2012;86:782-8.

12. Talundzic E, Okoth SA, Congpuong K, Plucinski MM, Morton L, Goldman IF, et al. Selection and spread of artemisinin-resistant alleles in Thailand prior to the global artemisinin resistance containment campaign. PLoS Pathog. 2015;11:e1004789.

13. Tamura K, Stecher G, Peterson D, Filipski A, Kumar S. MEGA6: Molecular Evolutionary Genetics Analysis version 6.0. Mol Biol Evol. 2013;12:2725-9.

14. Trager W, Jensen JB. Human malaria parasites in continuous culture. Science. 1976;5:673.

15. Basco LK, Heseltine E. Field application of in vitro assays for the sensitivity of human malaria parasites to antimalarial drugs. Geneva: World Health Organization; 2007.

16. Niederwieser I, Felger I, Beck HP. Plasmodium falciparum: expression of gametocyte-specific genes in monolayer cultures and malaria-positive blood samples. Exp Parasitol. 2000;95:163-9.

17. Menegon M, Severini C, Sannella A, Paglia MG, Sangaré D, AbdelWahab A, et al. Genotyping of Plasmodium falciparum gametocytes by reverse transcriptase polymerase chain reaction. Mol Biochem Parasitol. 2000;111:153-61.

18. Snounou G, Zhu X, Siripoon N, Jarra W, Thaithong S, Brown KN, et al. Biased distribution of msp1 and msp2 allelic variants in Plasmodium falciparum populations in Thailand. Trans R Soc Trop Med Hyg. 1999:93:369-74.

19. Huson DH, Richter DC, Rausch C, Dezulian T, Franz M, Rupp R. Dendroscope: an interactive viewer for large phylogenetic trees. BMC Bioinform. 2007;8:460.

20. Singh V, Mishra N, Awasthi G, Dash AP, Das A. Why is it important to study malaria epidemiology in India? Trends Parasitol. 2009;10:452-7.

21. White NJ. Antimalarial drug resistance. J Clin Invest. 2004;8:1084-92.

22. Onchiri FM, Pavlinac PB, Singa BO, Naulikha JM, Odundo EA, Farquhar $C$, et al. Frequency and correlates of malaria over-treatment in areas of differing malaria transmission: a cross-sectional study in rural Western Kenya. Malar J. 2015;14:97.

23. Prajapati SK, Joshi H, Shalini S, Patarroyo MA, Suwanarusk R, Kumar A, et al. Plasmodium vivax lineages: geographical distribution, tandem repeat polymorphism, and phylogenetic relationship. Malar J. 2011;10:374.

24. Dorsey G, Kamya MR, Singh A, Rosenthal PJ. Polymorphisms in the Plasmodium falciparum pfcrt and pfmdr-1 genes and clinical response to chloroquine in Kampala, Uganda. J Infect Dis. 2001;183:1417-20.

25. Djimdé A, Doumbo OK, Cortese JF, Kayentao K, Doumbo S, Diourté Y, et al. A molecular marker for chloroquine-resistant falciparum malaria. N Engl J Med. 2001;344:257-63.

26. Li J, Chen J, Xie D, Eyi UM, Matesa RA, Obono MM, et al. Molecular mutation profile of Pfcrt and Pfmdr1 in Plasmodium falciparum isolates from Bioko Island, Equatorial Guinea. Infect Genet Evol. 2015:36:552-6.

27. Ndiaye D, Dieye B, Ndiaye YD, Van Tyne D, Daniels R, Bei AK, et al. Polymorphism in dhfr/dhps genes, parasite density and ex vivo response to pyrimethamine in Plasmodium falciparum malaria parasites in Thies, Senegal. Intl J Parasitol Drugs Drug Resist. 2013;3:135-42.

28. Zakeri S, Afsharpad M, Raeisi A, Djadid ND. Prevalence of mutations associated with antimalarial drugs in Plasmodium falciparum isolates prior to the introduction of sulphadoxine-pyrimethamine as first-line treatment in Iran. Malar J. 2007;6:148.

29. Koleala T, Karl S, Laman M, Moore BR, Benjamin J, Barnadas C, et al. Temporal changes in Plasmodium falciparum anti-malarial drug sensitivity in vitro and resistance-associated genetic mutations in isolates from Papua New Guinea. Malar J. 2015;14:560.

30. Bates SJ, Winstanley PA, Watkins WM, Alloueche A, Bwika J, Happi TC, et al. Rare, highly pyrimethamine-resistant alleles of the Plasmodium falciparum dihydrofolate reductase gene from 5 African sites. J Infect Dis. 2004;10:1783-92

31. Kumar A, Moirangthem R, Gahlawat SK, Chandra J, Gupta P, Valecha N, et al. Emergence of sulfadoxine-pyrimethamine resistance in Indian 
isolates of Plasmodium falciparum in the last two decades. Infect Genet Evol. 2015;36:190-8.

32. Patel P, Bharti PK, Bansal D, Ali NA, Raman RK, Mohapatra PK, et al. Prevalence of mutations linked to antimalarial resistance in Plasmodium falciparum from Chhattisgarh, Central India: a malaria elimination point of view. Sci Rep. 2017;7:16690.

33. Hunt P, Martinelli A, Modrzynska K, Borges S, Creasey A, Rodrigues L, et al. Experimental evolution, genetic analysis and genome re-sequencing reveal the mutation conferring artemisinin resistance in an isogenic lineage of malaria parasites. BMC Genomics. 2010;11:499.

34. Wirjanata G, Handayuni I, Prayoga P, Leonardo L, Apriyanti D, Trianty L, et al. Plasmodium falciparum and Plasmodium vivax demonstrate contrasting chloroquine resistance reversal phenotypes. Antimicrob Agents Chemother. 2017;61:e00355.

35. http://icmr.nic.in/ijmr/2017/November/1109.pdf.

36. Warhurst DC. Polymorphism in the Plasmodium falciparum chloroquine-resistance transporter protein links verapamil enhancement of chloroquine sensitivity with the clinical efficacy of amodiaquine. Malar J. 2003;2:31

37. Anvikar AR, Sharma B, Sharma SK, Ghosh SK, Bhatt RM, Kumar A, et al. In vitro assessment of drug resistance in Plasmodium falciparum in five States of India. Indian J Med Res. 2012;135:494-9.

38. Gharbi M, Flegg J, Hubert V, Kendjo E, Metcalf J, Guerin PJ, et al. Longitudinal study assessing the return of chloroquine susceptibility of Plasmodium falciparum in isolates from travellers returning from West and Central Africa, 2000-2011. Malar J. 2013;12:35.
39. Bousema T, Okell L, Shekalaghe S, Griffin JT, Omar S, Sawa P, et al. Research revisiting the circulation time of Plasmodium falciparum gametocytes: molecular detection methods to estimate the duration of gametocyte carriage and the effect of gametocytocidal drugs. Malar J. 2010;9:136.

40. Nwakanma D, Kheir A, Sowa M, Dunyo S, Jawara M, Pinder M, et al. High gametocyte complexity and mosquito infectivity of Plasmodium falciparum in the Gambia. Int J Parasitol. 2008;38:219-27.

41. Drakeley CJ, Secka I, Correa S, Greenwood BM, Targett GA. Host haematological factors influencing the transmission of Plasmodium falciparum gametocytes to Anopheles gambiae s.s. mosquitoes. Trop Med Int Health. 1999;4:131-8.

42. Gosi P, Lanteri CA, Tyner SD, Se Y, Lon C, Spring M, et al. Evaluation of parasite subpopulations and genetic diversity of the msp 1 msp2 and glurp genes during and following artesunate monotherapy treatment of Plasmodium falciparum malaria in Western Cambodia. Malar J. 2013;12:403.

43. Bretscher MT, Valsangiacomo F, Owusu-Agyei S, Penny MA, Felger I, Smith T. Detectability of Plasmodium falciparum clones. Malar J. 2010;9:234.

\section{Publisher's Note}

Springer Nature remains neutral with regard to jurisdictional claims in published maps and institutional affiliations.
Ready to submit your research? Choose BMC and benefit from:

- fast, convenient online submission

- thorough peer review by experienced researchers in your field

- rapid publication on acceptance

- support for research data, including large and complex data types

- gold Open Access which fosters wider collaboration and increased citations

- maximum visibility for your research: over $100 \mathrm{M}$ website views per year

At BMC, research is always in progress.

Learn more biomedcentral.com/submissions 